\section{In Conversation with Will Falk, Partner, Accenture Health and Life Sciences}

Ken Tremblay

W illiam Falk has walked the back halls of power and has managed projects and teams that have set directions, shifted public policy and made headlines. No stranger to the complexities of the healthcare system, academic medicine and the drivers of change, Will has formed strong ideas and possible solutions from his observations in Canada and the US. Armed with these experiences, a passion to improve system performance, the promise of information technology and Canada's recent emphasis on wait times and chronic disease management, Will Falk, now with Accenture's Health and Life Sciences practice, has become a proponent of the enabled patient - participants who can better navigate the system and its providers. Ken Tremblay spoke with him at his Toronto office.

HQ: You served as an advisor to the Prime Minister during the 2004 First Ministers' Meeting (FMM). What were your thoughts then and now as you scan the healthcare system in Canada?

WF: I believe we need to stay focused on improving the public system. I had the chance to be on the floor in 2004 at the FMM, which made important steps towards that goal. It was an incredibly difficult process - balancing interests - but the result was pretty solid: more money for healthcare and with clear agreement on targets and a focus on what's important for patients.

A lot of people have described the " 5 in 5 " wait time programs as being too limited, and to some extent I agree with this. But by limiting the scope, you can get something done, get traction and get the progress we need for patients. I have no doubt that what we started in the first five wait time strategies will migrate into pediatrics and then into all surgery and eventually into chronic disease management.

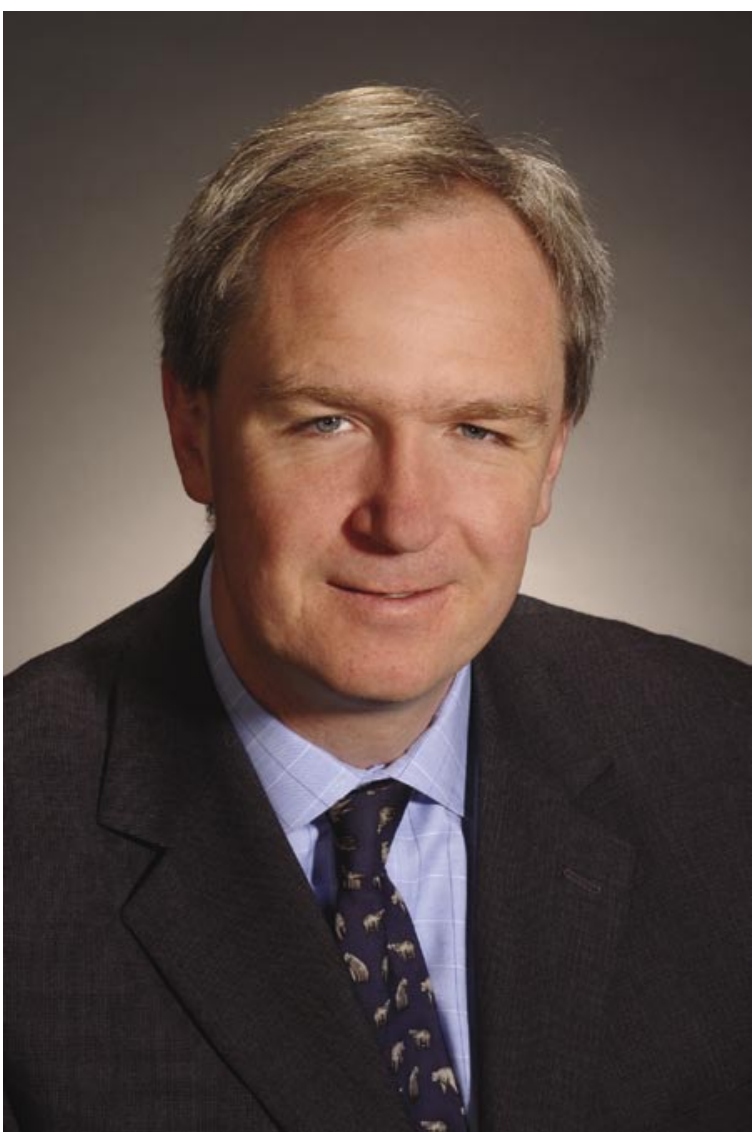

... the public healthcare system needs to be able to make clear promises to citizens about what it can deliver in terms of timely access and quality.

Wait times for surgeries and chronic disease management in medicine are really just two sides of the same coin. They rest on the same set of principles. We need to insist that the public system meets expectations for patients and ensure that people know how long it will take to receive care and what they will receive from their providers. The FMM 2004 started to change the incentives, to reward performance and move away from global budgets.

HQ: What is your take on Canada's approach to information technology, its deployment and acquisition in healthcare?

WF: Canada Health Infoway has been remarkably successful. What impresses me about Infoway is that it is an interesting Federal-Provincial-Territorial process innovation. Infoway has been able to get the various levels of government to work together; its unique governance model and approach to standards and funding are impressive. Also, it has attracted a lot of new talent into healthcare to accelerate the progress of transforming the system. 
With respect to the eHR, success cannot be dependent on getting $100 \%$ of the information, $100 \%$ of the time, for $100 \%$ of the patients. We can radically simplify the problem if we focus clinical information by condition and focus the early electronic records on sick people. I strongly support a closer link between chronic disease-specific investments and the creation of eHRs. If you look at health information in populations with specific needs, it makes a lot more sense to focus on that group than the general population. About $10 \%$ of the population accounts for about $50 \%$ of healthcare spending. The goal becomes a more manageable problem when you start with those patients before we build eHRs for healthy people.

HQ: This segues into knowledge management. How do you think knowledge management will change the healthcare workplace? Is there any facet of KM that particularly interests you?

WF: Two ways. First will be the rights of the consumer. We are already seeing consumers take control of their information, and that uptake is going to move faster in the future. People can and should take responsibility for their care and their electronic health record. Patient records are still too provider-centric. We need to allow and support people so they can take care of the information about their own condition.

One practical example is Medicalert, to whom hundreds of thousands of Canadians voluntarily pay money to hold and communicate their health information in emergency situations. It is not at all clear to me that government is the right vehicle for the storage of large amounts of healthcare data in the longterm. Provider organizations and third party not-for-profits seem much more likely.

Secondly, we need to "get the physical out of the fee schedule." When you call your lawyer or accountant for an answer to a question, you expect to get a bill for it. You should be able to do the same thing with your physician and expect it to be covered by the public system. Spending two hours in transit to handle a provider inquiry that could be done by phone or e-mail is not sensible. Managing knowledge and information more smartly, including tele-diagnosis, is possible and should be done now.

HQ: What have been your key messages to government?

WF: There have been five things: (1) declare a clear commitment to citizens; (2) let's get incentives right; (3) ensure data transparency; (4) system processes require redesign and in some cases transformation; and (5) invest in technology infrastructure.

On the clear commitment to citizens, particularly postChaoulli, the public healthcare system needs to be able to make clear promises to citizens about what it can deliver in terms of timely access, and quality. Most of our attention has been about timely access but a similar approach to quality is on the horizon in the next two years.

Sometimes, a clear access commitment can seem like gross oversimplification, but simple commitments from policy makers to citizens serve an important purpose in healthcare as in other industries. Just as when a pizza company says 30 minutes or it's free or a large bank promises access to a teller in five minutes or that government can get you a birth certificate in a week, this is how one drives change in large bureaucracies.

The second is aligning incentives with the clear promises. This point stems from the Kirby Report vis-à-vis global hospital budgets and fee-for-service for physicians. We have begun to move hospitals to a price-based system through the surgical wait times payments. Now we need to move FFS providers towards disease-management models. We need to incent a system that keeps people well and out of the system. Of course, the devil is in the details; there will be a lot of work on this in the next five years to end fee-for-service and global budgets as they currently exist. The next rounds of fee negotiations may contain an early indication of what's ahead.

When you pay for results, you get to the third piece - getting results and data reporting right. Alan Hudson has shown that successfully with information about access to care and surgical wait times. Before Hudson, people simply had no idea what costs were or how long the waits were in Ontario. This year, quality outcomes reporting is appearing on the agenda. This will accelerate when the CIHI Hospital Standardized Mortality Rate (HSMR) data are reported later this year or early next. That will drive even more system transformation.

When clinicians have and own the data, they will want to improve outcomes and their related processes. People will want to improve processes and results when the data gets reported. New data have already set off a round of detailed improvements in emergency rooms and around referral processes across the country. Further waves of clinical transformation will come as more data made available.

HQ: What challenges or issues would be most problematic for people if they were to follow your suggestions, say as a Deputy Minister, CEO or Health Authority?

WF: Keeping the focus on the clinical and business issues. To get adoption or early wins, you need to keep the benefits clearly in mind and drive changes from that perspective. It goes back to the gross oversimplification point. Focusing obsessively on a few measures is a way of communicating how and where you want the system to move. That clarity helps all of us.

At Accenture, we believe that system leaders need to be clear thinkers and re-examine data to debunk myths. Let me give you one example of a persistent myth: we all think healthcare costs are going up across the board in our publicly funded healthcare system. In fact, while total costs are going up, unit costs are generally going down - efficiencies are occurring and working 
in many areas. Case in point: the price for cataract surgery has dropped in the last two decades from several thousand dollars to a few hundred. The same is true in many diagnostics, medical devices, and drugs. We can run a great affordable system if we are smart about costs.

HQ: We hear a lot about P3/AFAs for hospital construction - bricks and mortar. Any thoughts about how we might build Canada's e-health strategy using this approach?

WF: I think it's a good idea to examine. We did something interesting when Canada organized its public hospital system in Emmett Hall's vision. We accidentally separated capital decisions from operational decisions. If you think about running a business, the $\mathrm{CEO}$ controls both capital and operational decisions, right? In healthcare, capital decisions were centralized and operational decisions stayed in the hands of management. The result is that we've systematically favoured labour over capital because it was easier for hospital administrations to handle the operational side than deal with the capital side. The effect is that we starved the system of capital and now IT as well as bricks and mortar have huge requirements.

I wonder whether we shouldn't be consciously returning capital decisions to managers across the whole system. Hold them accountable and give them the responsibility. It might mean we need some kind of certificate of need process. One thing is clear though; whatever we do we can't call it "privatepublic partnership" because that terminology gets a lot of people really upset.

\section{Enabling the patients, rather than treating} them as passive participants, is an important piece to system transformation.

HQ: In the new world of public accountability, how have you seen the role of central government change?

WF: Kirby and Chaoulli changed accountability forever in the Canadian healthcare system, and fundamentally. Both the Martin and Harper governments recognized that change. There is now a broad multi-party consensus on this point. The federal government has been pretty good about making clear and specific commitments to Canadians, as have several provinces, particularly Ontario. What is fascinating is that regardless of party or province, there's general agreement on the principle that citizens have a right to expect timely access to quality care, and have a right to know about how the system is performing and about outcomes. I don't think that has permeated all the ministries yet. There are a lot of well-meaning people who have grown up in a world of healthcare myths and need help taking a fresh look at data. It's a dynamic process and will take time. There are many CEOs and providers leading the way who are committed to change. If we are going to insist upon a vibrant public system, we're going to have to make it happen.

HQ: Tell us more about the enabled patient. How do you see the information age helping patients and their families? WF: It is the notion about building the eHR based on diseasespecific factors. There is a lot of data noise in the data we collect and it sits in paper files. It's a question of how you make sense of it to better care for the patient. Enabling patients means using their condition as a filter through which we view the data so that you can see what's going on and it allows for better organization. It links back to the whole idea that the eHR should probably rest with or be accessible to the individual and the family. There's a good case to be made that the core data set should be sitting with the patient as you go through life and would be linked to more complex data sets with providers. But enabling patients to take control of their own record is a way of improving the quality of information and how we organize care. Enabling the patients, rather than treating them as passive participants is an important piece to system transformation. After all, it is their care.

HQ: Lessons learned from managing wait times have opportunities for chronic disease management. Tell us more.

WF: Recent CIHI data were pretty definitive that the "five in five" priorities haven't crowded out other conditions. The CMA and others have called for this approach to be expanded to all surgeries. When that happens, the medical side of the house will begin asking the same sort of "balloon effect" question. The question will become: What's the analog on the medical side? What's the simple commitment by the health system for patients with diabetes, asthma or congestive heart failure?

There has been good work and thinking in disease management and prevention for more than a generation, certainly back to Lalonde. The "Kirby question" is how you change the incentives so that you unlock system transformation. Is it as simple as a promise to citizens that they will be kept away from the emergency room because we'll you a good job managing their case over time? Should we be paying MDs who are successful at keeping their patients well? Does it need to be something more complex than that? I don't claim to know the answer, but I think that's where the debate is heading. We have to be able to get the data, make the commitments and change the funding system to change the medical side the way we made changes on the surgical side.

I completely agree that a new level of thinking is required, and I'm not claiming that the answer is a simple one. I would say that it is probably around emergency department utilization. 
The shape of the solution is some kind of contract capitation model that pays the multidisciplinary clinician group for taking care of a patient over time and with incentives for achieving predetermined outcomes or results.

We do need to tackle this piece. There's a lot of money in the system going towards non-value-added stuff that can be redirected to other needs. And just like some surgical wait times, if we overpay a few physicians for a year or two to get the system moving, it's okay.

HQ: Who have you admired most as a leader in the healthcare system and why?

WF: Two people: first, Alan Hudson because he leads with clarity and good judgment, and his ability to make business and clinical trade-offs is unmatched. He is a wonderful thinker on these issues and the most completely direct person I have ever met.

Then Michael Kirby because of his ability to master many complex files; he's a guy who has taken tough issue after tough issue and solved it. From fisheries to mental health, he is a great independent and practical thinker. I am so impressed by that ability.
HQ: Anything else you think the readers of Healthcare Quarterly might want to know about you?

WF: My parting comment is that there is urgency to transform the public healthcare system. Chaoulli and privatization are warning shots across our bow that we need to step up our game, and fully transform healthcare in Canada. $\mathbf{H Q}$

\section{Thank you}

for supporting Breakfast with the Chiefs

\section{Baxter AGFA}

Health Care

Longwoods Publishing Enabling Excellence

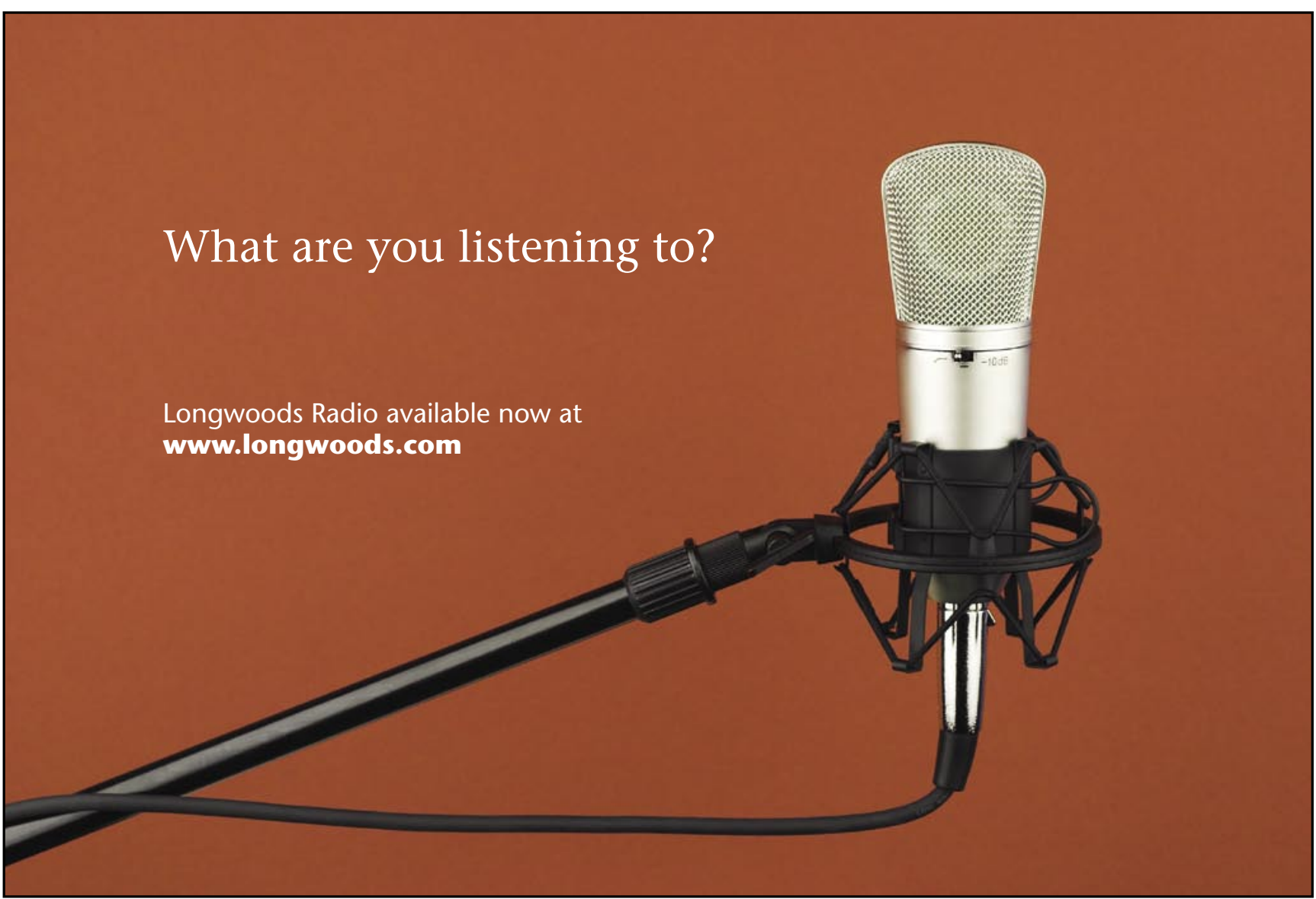

